\title{
Crowding with Negatively Conditioned Flankers and Targets
}

\author{
Ferdinand Pittino, Lisa Valentina Eberhardt, Anja Kurz, and Anke Huckauf
}

General Psychology, Institute of Psychology and Education, Ulm, Ulm University, Ulm, Germany

ABSTRACT

\section{KEYWORDS}

crowding;

emotion;

critical spacing;

evaluative conditioning

Crowding refers to the phenomenon of increased difficulty in identifying a peripherally presented stimulus when it is surrounded by adjacent flankers compared to when it is presented in isolation. The aim of the present study was to investigate the influence of flanker and target emotion on crowding effects. Therefore, Landolt rings with certain opening directions were conditioned with neutral or negative pictures. These conditioned stimuli were afterwards used in a visual crowding task, in which the critical spacing (75\% threshold) was assessed for emotional flankers as well as for emotional targets. Larger crowding effects were observed for negatively relative to neutrally conditioned flankers, indicating more interference with negative flankers. Additionally, for participants showing a strong evaluative conditioning effect, smaller crowding effects were found for negatively relative to neutrally conditioned targets, indicating enhanced identification of negative target stimuli. In conclusion, crowding effects are modulated by both flanker and target emotion, suggesting that high-level stimulus features survive crowding and influence recognition performance. The study further shows that evaluative conditioning can be a useful tool to study the effect of emotion on rather early perceptual processes.

\section{INTRODUCTION}

Even though peripheral vision is degraded compared to foveal vision (e.g., Rosenholtz, 2016), peripheral vision is highly important for guiding overt and covert attentional movements (e.g., Lambert, Naikar, McLachlan, \& Aitken, 1999; Parkhurst, Law, \& Niebur, 2002). According to Rosenholtz (2016), the main limiting factor of peripheral vision is crowding, which is defined as the increased difficulty in identifying an object in the visual periphery when it is surrounded by adjacent flankers compared to when it stands in isolation (e.g., Levi, 2008; Pelli, Palomares, \& Majaj, 2004; Pelli \& Tillman, 2008; Whitney \& Levi, 2011). In general, crowding proves to be a robust effect, which is observable in every participant and, therefore, is usually detected with rather small sample sizes (e.g., $n=3$ in Nazir, 1992; $n=7$ in Pelli et al., 2004). Furthermore, it is well acknowledged that crowding effects are larger the more eccentric the presented stimuli and the smaller the lateral distances (spacing) between the target and the flankers (e.g. Bouma, 1970). This major dependency of crowding on eccentricity, spacing, and their interaction suggests that low-level factors contrib-

Corresponding author: Ferdinand Pittino, General Psychology, Institute of Psychology and Education, Ulm University, Albert-Einstein-Allee 47, 89069 UIm, Germany. E-mail: ferdinand.pittino@alumni.uni-ulm.de 
ute to crowding. The processes underlying crowding are highly disputed (for an overview see Levi, 2008; Whitney \& Levi, 2011). Various theoretical accounts differ regarding the stage of processing at which crowding is supposed to occur. According to early perceptual accounts, crowding may, for example, occur because of larger receptive fields in the visual periphery, which might result in lower visual resolution and pooling of target and flanker features (for an overview see Levi, 2008, Whitney \& Levi, 2011). However, other accounts stress that crowding depends on higher cognitive processing and is therefore modulated by attention (e.g., decreased attentional resolution in the periphery as well as endogenous and exogenous attentional shifts; for an overview see Levi, 2008; Whitney \& Levi, 2011).

Hence, an important question for crowding, and therefore also for our understanding of the functioning of peripheral vision, is to what extent high-level stimulus features such as emotion are processed when the stimulus is presented in crowded conditions in the periphery. Thus, one question is whether stimulus emotion impacts recognition performance of stimuli presented in visual clutter in the periphery. If crowding is solely based on the (resolution) limitations of our visual system, the emotional meaning of the flanker and target stimuli should not impact the identification of the target stimulus. Even though crowding significantly impairs target identification, studies suggest that highlevel, semantic features of crowded stimuli are still processed and can elicit behavioral outcomes (Atas, Faivre, Timmermans, Cleeremans, \& Kouider, 2014; Faivre, Berthet, \& Kouider, 2012; Huckauf, Knops, Nuerk, \& Willmes, 2008; Kouider, Berthet, \& Faivre, 2011; Yeh, He, \& Cavanagh, 2012). For example, Kouider et al. (2011) demonstrated that preference judgements are biased by the preceding presentation of crowded emotional stimuli: They presented happy or angry faces in the visual periphery and surrounded those with pattern-noise flankers. Afterward, participants had to indicate whether an unknown Chinese pictograph has a positive meaning or not. Even though subjects had difficulties identifying the crowded facial expressions, the prime stimulus biased the preference judgements. Thus, the Chinese pictographs were rated to be more pleasant when they were preceded by happy compared to angry faces. Given that the emotional content of flanked stimuli seems to be processed despite crowding and was shown to have effects on unrelated tasks (e.g., Kouider et al., 2011), one might wonder whether recognition performance (identification) of crowded stimuli is also influenced by flanker and target emotion. The present study is the first time this issue is investigated.

Given that emotional stimuli were shown to be more distracting than neutral ones (e.g., Carretié, 2014; Hodsoll, Viding, \& Lavie, 2011; Schimmack, 2005; Yiend, 2010, Zadra \& Clore, 2011), one could argue that the identification of a crowded target is more impaired by affective compared to neutral flankers (e.g., Freeman, Sagi, \& Driver, 2001).

Further, emotion research commonly suggests a strong bias toward affective stimuli, indicating prioritized processing of valenced objects (e.g., Carretié, 2014; Yiend, 2010, Zadra \& Clore, 2011). In line with this argumentation, one might further expect that a crowded target is easier to be identified when it is affectively valenced compared to neutral.
A common problem in studying the influence of emotion on cognitive processing consists in a possible confounding of high-level emotional effects with effects based on low-level sensorial factors (e.g., Horstmann, Borgstedt, \& Heumann, 2006; Lakens, Fockenberg, Lemmens, Ham, \& Midden, 2013). For example, Lakens et al. (2013) demonstrated that negative pictures of the commonly used International Affective Picture System (IAPS; Lang, Bradley, \& Cuthbert, 2008) are significantly darker than neutral ones. To control for such sensorial confounds, it is necessary to use stimuli which are comparable regarding all low-level features, and only differ regarding their high-level, affective content. This can be achieved by employing the evaluative conditioning (EC) paradigm (e.g. Kliegl, Watrin, \& Huckauf, 2015; Pittino, Kliegl, \& Huckauf, 2018). In general, EC is defined as the change in liking of a conditioned stimulus (CS) due to its repeated pairings with an affective unconditioned stimulus (UCS; De Houwer, Thomas, \& Baeyens, 2001; Hofmann, De Houwer, Perugini, Baeyens, \& Crombez, 2010). For example, Kliegl et al. (2015) and Pittino et al. (2018) conditioned Landolt rings with opposing gap positions (e.g., gap position "left" vs. gap position "right") with neutral or negative IAPS pictures. Following this conditioning procedure, the CS paired with negative stimuli $\left(\mathrm{CS}_{\text {negative }}\right)$ was rated to be more negative and more arousing than the CS paired with neutral stimuli $\left(\mathrm{CS}_{\text {neutral }}\right)$. Importantly, previous studies suggest that EC procedures not only result in changes in explicit ratings of valence and arousal, but that evaluatively conditioned stimuli also elicit similar reactions compared to the affective UCS, that is, changes in physiological and behavioral responses (Batty, Cave, \& Pauli, 2005; Kliegl et al., 2015; Pittino et al., 2018; Pittino, Kliegl, \& Huckauf, 2016). Further evidence for affective processing of conditioned stimuli arises from studies employing fear conditioning procedures, in which electric shocks or white noise bursts are used as aversive UCS (e.g., Koster, Crombez, Van Damme, Verschuere, \& De Houwer, 2005; Notebaert, Crombez, van Damme, Houwer, \& Theeuwes, 2011; Schmidt, Belopolsky, \& Theeuwes, 2015; Stormark, Hugdahl, \& Posner, 1999). For example, Koster et al. (2005) found differential fear conditioning effects on attentive processing in an exogenous cueing task. When the stimulus paired with noise bursts cued the location of the target, participants were faster in reporting the target location compared to when the stimulus not paired with noise bursts served as cue. Thus, the CS paired with noise bursts was shown to capture attention more strongly than the CS not associated with this aversive UCS. Furthermore, on invalid trials, in which the CS cued the opposite location, participants responded slower when this location was cued by the CS paired with noise bursts compared to the other one. In conclusion, fear conditioned stimuli seem to not only capture, but also hold attention more strongly. Hence, previous work showed that CS paired with aversive UCS are preferred in processing, as assessed by reaction time measures. However, to our knowledge, no previous study provided a quantification of the effects of emotional flanker and target stimuli on crowding.

Therefore, in the present study, we employed the method of EC to investigate the effects of conditioned target and flanker emotion on crowding-thus, on the identification of peripherally presented, 
flanked stimuli. Landolt rings with opposing gap positions were used as CS and each gap position was either paired with neutral or negative pictures. These CS, which are comparable regarding their visual features and only differ in their evaluative learning history, were then administered as flankers and as targets in a visual crowding task. Given that affective stimuli are more distracting than neutral ones (e.g., Schimmack, 2005), one should expect stronger crowding effects when targets are surrounded by $\mathrm{CS}_{\text {negative }}$ compared to $\mathrm{CS}_{\text {neutral }}$ flankers. According to assumptions of prioritized processing of affective stimuli (e.g., Yiend, 2010), one should further expect reduced crowding effects for negatively conditioned $\left(\mathrm{CS}_{\text {negative }}\right)$ compared to neutrally conditioned target stimuli $\left(\mathrm{CS}_{\text {neutral }}\right)$. Indeed, this is the pattern the results of the present study suggest. In general, the experimental method was similar to the studies of Kliegl et al. (2015) and Pittino et al. (2018).

\section{METHODS}

\section{Participants}

Twenty psychology students of Ulm University (two males, $\left.M_{\text {age }}=21.65, S E_{\text {age }}=0.92\right)$ participated in this experiment in exchange for partial course credit. All subjects were naïve about the hypotheses and had normal or corrected to normal vision. They all read and signed a written consent form, which was based on the guidelines of the German Research Foundation (DFG).

\section{Apparatus}

The procedure was implemented in Matlab (Version 13b; Mathworks Inc.) using the Psychophysics Toolbox extension (Version 3.0.12; Brainard, 1997; Pelli, 1997) and was run on a Windows 8 computer. The stimuli were presented on an Acer GN246HLB monitor (1920 x $1080 \mathrm{px}, 60 \mathrm{~Hz}$ refresh rate). A chin rest ensured a constant viewing distance of approximately $60 \mathrm{~cm}$.

\section{Stimuli}

Twenty negative and 20 neutral IAPS pictures (Lang et al., 2008) were employed as UCS, as described by Kliegl et al. (2015). The IAPSpictures were presented centrally with a size of $26^{\circ} \times 19.5^{\circ}$. Two black Landolt rings (EN ISO 8596) with opposing gap positions (up vs. down or left vs. right; see Figure 2 for an example) served as CS. The CS were presented centrally with a size of $1^{\circ}$ on a grey background. Hence, the CS were identical regarding all sensorial features, because the Landolt rings only differed regarding their gap position. The assignment of the gap position to the valence of the UCS (negative vs. neutral) was counterbalanced across participants. Four corners of a centrally presented, black, $1.2^{\circ}$ square served as fixation stimuli during evaluative conditioning. A $0.6^{\circ}$ central, black fixation cross served as a visual cue in the crowding task.

\section{Procedure}

\section{OVERVIEW}

The procedure is illustrated in Figure 1. After being informed about the experiment, participants were first familiarized with the crowding task. Participants then rated several stimuli regarding valence and arousal. Then, evaluative conditioning was administered, and participants again rated the now evaluatively conditioned stimuli. Afterward, participants performed the crowding task, which was interrupted for repetitions of conditioning. Finally, the CS were again evaluated. Overall, the experiment lasted for about 75 minutes.

\section{RATING}

Rating started with presenting an overview of the 20 negative and 20 neutral IAPS pictures (Kliegl et al., 2015; Pittino et al., 2018). Participants then rated these IAPS pictures and the Landolt Rings on the valence and arousal subscales of the self-assessment-manikin (SAM) scale (Bradley \& Lang, 1994). Based on these ratings, the UCS were individually selected for each participant in the following way: As neutral UCS, the five neutrally rated pictures (valence rating between 4 and 6) with the lowest arousal ratings were selected. As negative UCS, the five negatively rated pictures (valence rating smaller than 4 ) with the highest arousal ratings were selected (Kliegl et al., 2015, Pittino et al., 2018). Rating of the Landolt rings (CS) was repeated after conditioning and after the crowding task. All pictures were presented in randomized order within each rating.

\section{EVALUATIVE CONDITIONING}

The evaluative conditioning procedure was very similar to the ones employed by Kliegl et al. (2015) and Pittino et al. (2018): A conditioning trial began with presenting the fixation square for a mean

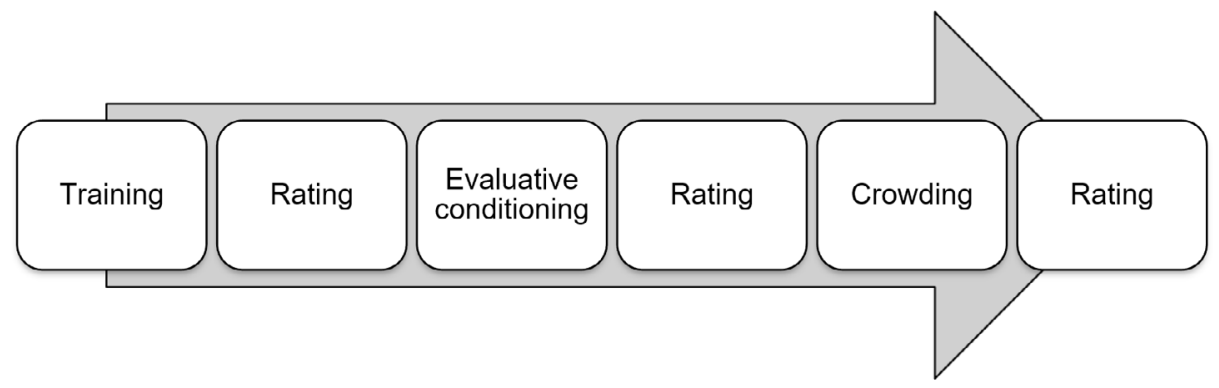

FIGURE 1.

IIllustration of the experimental procedure. 


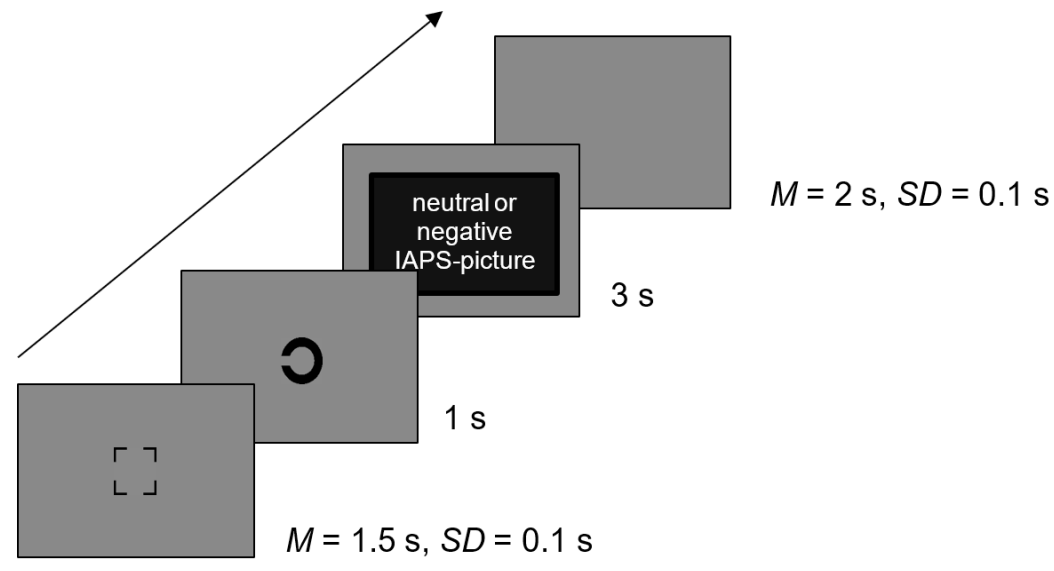

FIGURE 2.

Illustration of the evaluative conditioning (EC) procedure. The Landolt rings (conditioned stimuli, CS) were repeatedly followed by leither neutral or negative pictures from the International Affective Picture System (unconditioned stimuli, UCS).

duration of $1.5 \mathrm{~s}(S D=0.1 \mathrm{~s}$, see Figure 2). Then, one of the CS (e.g., a Landolt ring with left gap position) was presented for $1 \mathrm{~s}$. Afterwards, the respective UCS was presented (e.g., a negative IAPS-picture) for 3 s. Finally, a trial terminated with an empty intertrial interval with a mean duration of $2 \mathrm{~s}(S D=0.1 \mathrm{~s})$. Each CS was paired three times with each of the five individually selected UCS, resulting in 15 conditioning trials per CS. Before conditioning, the participants were instructed to carefully watch the stream of pictures and to pay close attention to the relation between the CS and the UCS. Other than that, the participants had no other task during conditioning. The trials were randomized throughout conditioning.

\section{CROWDING}

After conditioning, the $\mathrm{CS}_{\text {negative }}$ (e.g., a Landolt ring with left gap position), the $\mathrm{CS}_{\text {neutral }}$ (e.g., a Landolt ring with right gap position), as well as the two additional Landolt rings that were not conditioned (e.g., with an $u p$ and down gap position) were used as flanker and as target stimuli in a crowding task. Hence, there were four crowding conditions: In two conditions, the evaluatively conditioned stimuli $\left(\mathrm{CS}_{\text {negative }}\right.$ and $\mathrm{CS}_{\text {neutral }}$ ) were used as flankers and the additional Landolt rings not included in the conditioning procedure were used as the respective targets. In the other two conditions, the evaluatively conditioned stimuli were used as targets and the Landolt rings exempt from conditioning served as flankers (see Figure 3 for an illustration of the experimental conditions). The task was to identify the gap position of the middle target stimulus. In all conditions, both Landolt rings exempt from conditioning (e.g., gap position down and $u p$ ) were used equally often as flanker or target stimuli.

As the dependent variable, critical spacing was adaptively determined for the flanker as well as the target emotion. Critical spacing refers to the distance between the target and the flankers (center-tocenter distance) at which the individual participant recognizes the target correctly at a rate of $75 \%$. Larger critical spacing indicates higher difficulty in identifying the target, that is, stronger crowding effects.

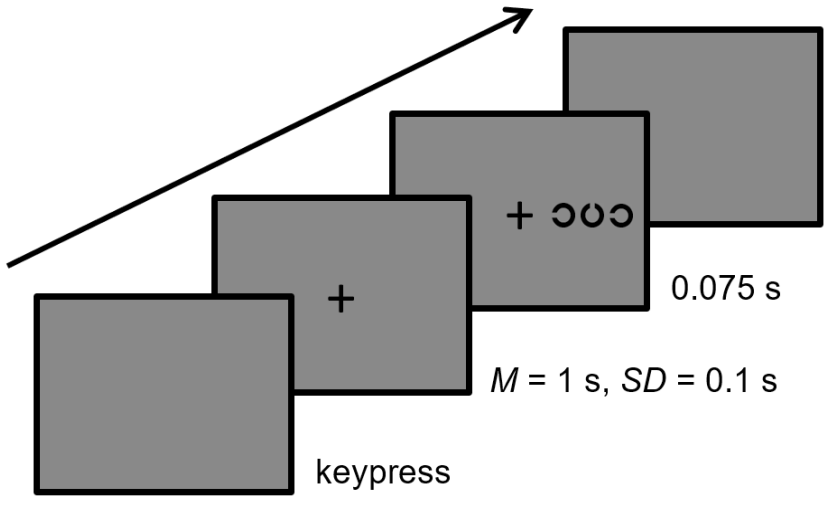

FIGURE 3.

Illustration of the crowding task procedure. Subsequently to the fixation cross, the target with the adjacent flankers appeared on the screen. The critical spacing was determined for four conditions: (a) not-conditioned (neutral) targets were surrounded by the $\mathrm{CS}_{\text {negative }}$ and the $\mathrm{CS}_{\text {neutral }}$ flankers, (b) $\mathrm{CS}_{\text {negative }}$ and $\mathrm{CS}_{\text {neutral }}$ targets were surrounded with not-conditioned (neutral) flankers. 
Target stimuli were always presented at $4^{\circ}$ of eccentricity and were flanked by the same Landolt rings on the left and right side. For each of the four stimulus conditions (negative/neutral flanker and negative/ neutral target valence), spacing was controlled by an adaptive Bayesian QUEST function (Watson \& Pelli, 1983). The initial slope parameter $\beta$ was set to $3.5 \mathrm{deg}^{-1}$ and the guess rate was set to the chance level of $25 \%$. Based on piloting stimulus size and eccentricity, the spacing was restricted to vary between $1^{\circ}$ and $4^{\circ}$.

Participants were instructed to identify the target's gap position as accurately and as fast as possible by keypress on a modified numeric keypad. A trial started after the participant pressed 5 on the keypad. A central fixation cross was presented for a mean duration of $1 \mathrm{~s}$ $(S D=0.1 \mathrm{~s}$, see Figure 3 for an illustration of the procedure). Afterward, the target was either presented in the left or right visual field at $4^{\circ}$ of eccentricity for $0.075 \mathrm{~s}$, together with two identical flanker stimuli. For each crowding condition, the respective center-to-center spacing was updated by the QUEST function on each trial. Participants indicated the gap position of the target Landolt ring by pressing either 8 (gap position $u p$ ), 2 (gap position down), 4 (gap position left) or 6 (gap position right) on the keypad.

Each of the four obtained critical spacings are based on 192 trials. The 768 trials were carried out in 12 blocks, each containing 64 trials. Within the blocks, presentation was randomized with the restriction of not more than four consecutive presentations in the same visual field. Similar to Kliegl et al. (2015) and Pittino et al. (2018), repetitions of conditioning were carried out between the blocks, since it is still unclear whether EC is resistant to extinction (De Houwer et al., 2001; Hofmann et al., 2010; Lipp \& Purkis, 2006). The procedure was identical to the initial conditioning except that each UCS was only repeated once, that is, there were five conditioning trials per CS.

At the beginning of the experiment, participants were familiarized with the crowding task. The procedure was identical to one block of the outlined test phase, except that spacing was fixed at $2.5^{\circ}$ and participants received auditory feedback.

\section{Statistical Analysis}

All data were analyzed using SPSS (version 24, IBM). In all analyses, the commonly used $\alpha$-level of .05 was applied.

\section{RESULTS}

\section{Ratings and Manipulation Check}

The valence and arousal ratings were entered in repeated-measures analyses of variance (ANOVAs) with the within-subject factors of CS $\left(\mathrm{CS}_{\text {neutrall }}, \mathrm{CS}_{\text {negative }}\right)$ and Moment (before conditioning, after conditioning, after crowding task). For valence ratings, the analysis revealed significant main effects of CS, $F(1,19)=15.78, p=.001, \eta_{\text {part }}^{2}=.454$, and moment, $F(2,38)=7.34, p=.002, \eta_{\text {part }}^{2}=.279$. Further, the interaction of CS and moment, $F(2,38)=14.64, p<.001, \eta_{\text {part }}^{2}=.435$ (see Figure 4), shows the common EC effect: Before conditioning, the valence ratings of the Landolt rings did not significantly differ, $\Delta M=-0.20, S E=$ $0.14, p=.163$. After the repeated pairings of the CS and the UCS, the $\mathrm{CS}_{\text {negative }}$ were rated to be more negative than the $\mathrm{CS}_{\text {neutral' }} \Delta M=0.65, \mathrm{SE}$ $=0.23, p=.012$. This acquired change in valence was still observable after the crowding task, $\Delta M=1.30, S E=0.26, p<.001$.

Also for arousal ratings, the analysis revealed main effects of CS, $F(1,19)=16.77, p=.001, \eta_{\text {part }}^{2}=.469$, and moment, $F(2,38)=9.41$, $p<.001, \eta_{\text {part }}^{2}=.331$ and an interaction of CS $\times$ moment, $F(2,38)=3.71, p=.034, \eta_{\text {part }}^{2}=.163$ (see Figure 4): Before conditioning, arousal ratings tended to differ between the Landolt rings, $\Delta M=-0.25, S E=0.12, \mathrm{p}=.056$. After conditioning $(\Delta M=-1.15, S E=$ $0.37, p=.005)$ and after the crowding task $(\Delta M=-1.70, S E=0.58, p$ $=.008)$, the $\mathrm{CS}_{\text {negative }}$ were rated with significantly higher arousal than the $\mathrm{CS}_{\text {neutral }}$

In sum, the evaluative ratings did not differ before conditioning. After conditioning, the $\mathrm{CS}_{\text {negative }}$ were rated to be more negative and more arousing than the $\mathrm{CS}_{\text {neutral }}$. This effect was still observable after
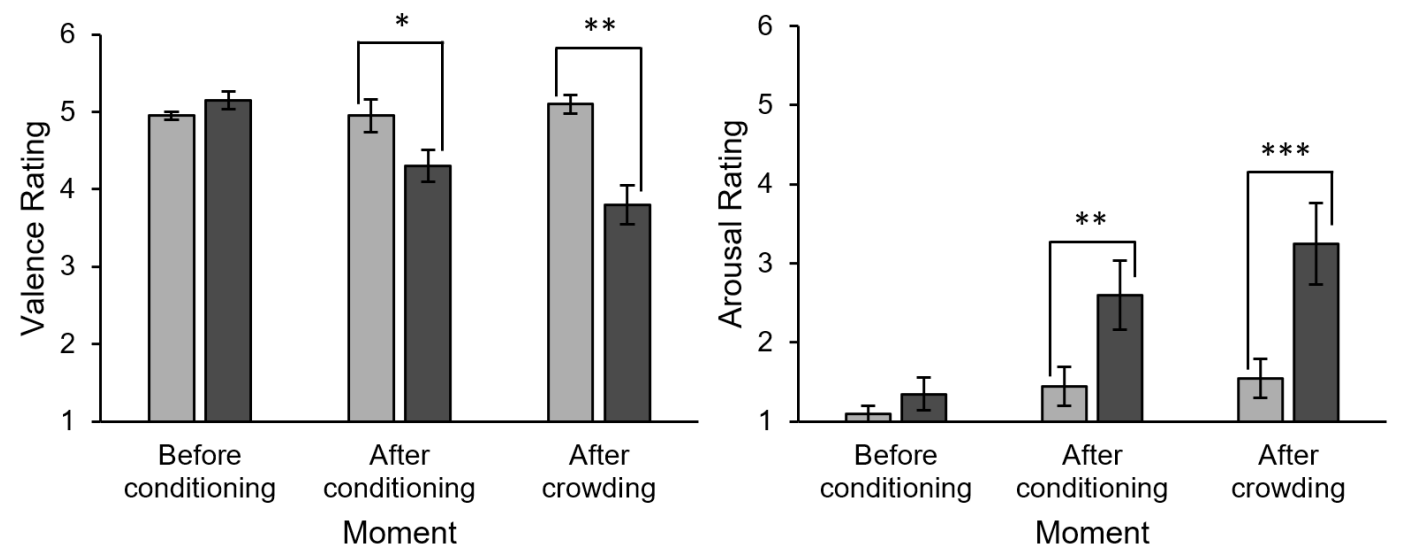

口neutral

口negative

\section{FIGURE 4.}

Left: Mean valence ratings for Landolt rings either repeatedly paired with the negative or the neutral UCS before conditioning, after conditioning, and after the crowding task. Right: Mean arousal ratings for the same conditions. Error bars indicate the SEM. ${ }^{*} p<.05,{ }^{* *} p<.01,{ }^{* * *} p<.001$. 
.001 .

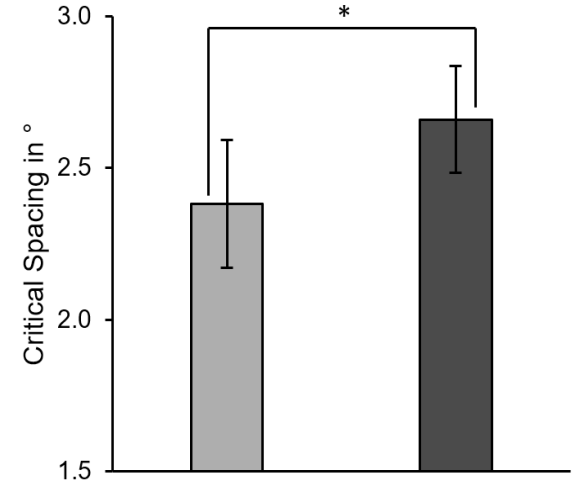

Flanker

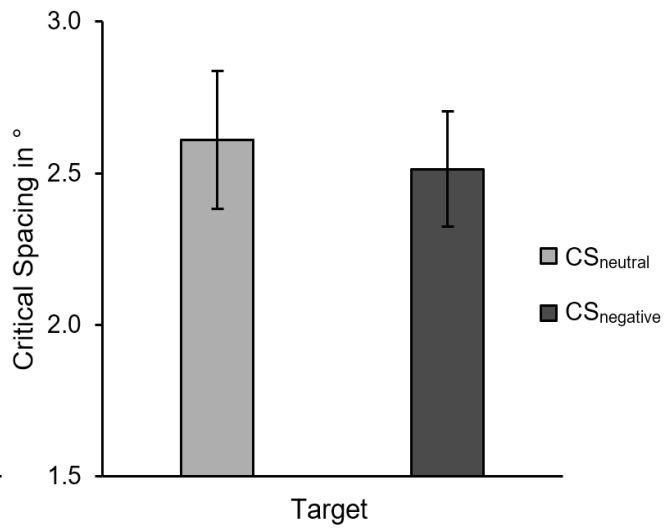

\section{FIGURE 5. $* p<.05$ \\ the crowding task, in which the CS were repeatedly presented without the respective UCS. Hence, the manipulation check shows that EC was generally successful. \\ Effects of Conditioned Flanker and Target Emotion on Crowding}

Mean critical spacings (75\% thresholds) for conditioned flanker and for conditioned target emotion. Error bars indicate the SEM

First, the influence of conditioned flanker emotion on crowding was examined. A paired-samples $t$-test indicated that critical spacings were significantly larger for $\mathrm{CS}_{\text {negative }}\left(M=2.66^{\circ}, S E=0.18^{\circ}\right)$ compared to $\mathrm{CS}_{\text {neutral }}$ flankers $\left(M=2.38^{\circ}, S E=0.21^{\circ}\right), t(19)=-2.23, p=.038$, $d=-0.498$ (see Figure 5).

Second, the influence of target emotion on crowding was examined. A paired-samples $t$-test indicated no significant differences between $\mathrm{CS}_{\text {negative }}\left(M=2.51^{\circ}, S E=0.19^{\circ}\right)$ and $\mathrm{CS}_{\text {neutral }}$ targets $\left(M=2.61^{\circ}\right.$, $\left.S E=0.23^{\circ}\right), t(19)=0.48, p=.635, d=0.108$ (see Figure 5).

\section{Post Hoc Analysis}

The analyses so far suggest significant effects for conditioned flanker emotion, but not for conditioned target emotion. Before inferring no influence of conditioned target emotion, we wanted to make sure that the effect does not depend on possible moderator variables. Since we used evaluatively conditioned stimuli, the strength of EC was considered as a possible moderator in the post hoc analysis. Therefore, the variable of EC strength was computed as the difference in valence ratings after conditioning. That is, for each participant, the valence ratings of the $\mathrm{CS}_{\text {negative }}$ were subtracted from the valence ratings of the $\mathrm{CS}_{\text {neutral }}\left(\mathrm{CS}_{\text {neutral }}-\mathrm{CS}_{\text {negative }}\right)$. Using a median-split based on EC strength $(M d n=0.5)$ the sample was equally divided in subjects showing a rather weak EC effect (EC strength $<0.5$ ) and participants showing a rather strong EC effect (EC strength $>0.5$ ).

The critical spacings for $\mathrm{CS}_{\text {negative }}$ and $\mathrm{CS}_{\text {neutral }}$ targets were entered in a repeated-measures ANOVA with the within-subject factor of CS $\left(\mathrm{CS}_{\text {negative }}, \mathrm{CS}_{\text {neutral }}\right)$ and the between-subject-factor of EC Strength (weak EC, strong EC). A significant interaction between CS and EC strength emerged, $F(1,18)=6.68, p=.019, \eta^{2 \text { part }}=.271$ (see Figure 6).
For weak EC, no difference in critical spacing between differentially conditioned targets was observed, $\Delta M=-0.36^{\circ}, S E=0.25^{\circ}, p=.167$. However, for strong EC, critical spacing was significantly smaller for CSnegative relative to CSneutral targets, $\Delta M=0.55^{\circ}, S E=0.25^{\circ}$, $p=.040$. The main effects were not significant $(F<0.4$ in both cases $)$.

\section{DISCUSSION}

The aim of the present study was to investigate for the first time whether the identification of a crowded target stimulus is influenced by flanker and/or target emotion. To control for possible low-level differences between negative and neutral stimuli (Horstmann et al., 2006; Lakens et al., 2013), we employed the EC paradigm and repeatedly paired Landolt rings with opposing gap positions with either neutral $\left(\mathrm{CS}_{\text {neutral }}\right)$ or negative ( $\left.\mathrm{CS}_{\text {negative }}\right)$ IAPS pictures (Kliegl et al., 2015; Pittino et al., 2018). These CS were afterwards used as flankers and as targets in a visual crowding task. Critical spacing ( $75 \%$ threshold) served as the dependent variable.

The subjective valence and arousal ratings replicated the common EC effect (De Houwer et al., 2001; Gawronski \& Mitchell, 2014; Hofmann et al., 2010; Kliegl et al., 2015; Pittino et al., 2018): After conditioning, the Landolt rings repeatedly paired with negative pictures $\left(\mathrm{CS}_{\text {negative }}\right)$ were rated to be more negative and more arousing than the Landolt rings associated with neutral pictures $\left(\mathrm{CS}_{\text {neutral }}\right)$. Further, this conditioned change in subjective ratings was still observable after the last block of the crowding task (after 32 CS-only presentations), which speaks in favor of the often proclaimed, but disputed resistance of EC to extinction (Baeyens, Díaz, \& Ruiz, 2005; Gawronski, Gast, \& De Houwer, 2015; Hofmann et al., 2010; Lipp \& Purkis, 2006; Pittino et al., 2018). In conclusion, the EC procedure was overall successful in changing the evaluation of the CS.

In general, emotional stimuli are prioritized in processing and hence, are more distracting than neutral stimuli (e.g., Carretié, 2014; Hodsoll et al., 2011; Schimmack, 2005; Yiend, 2010, Zadra \& Cole, 


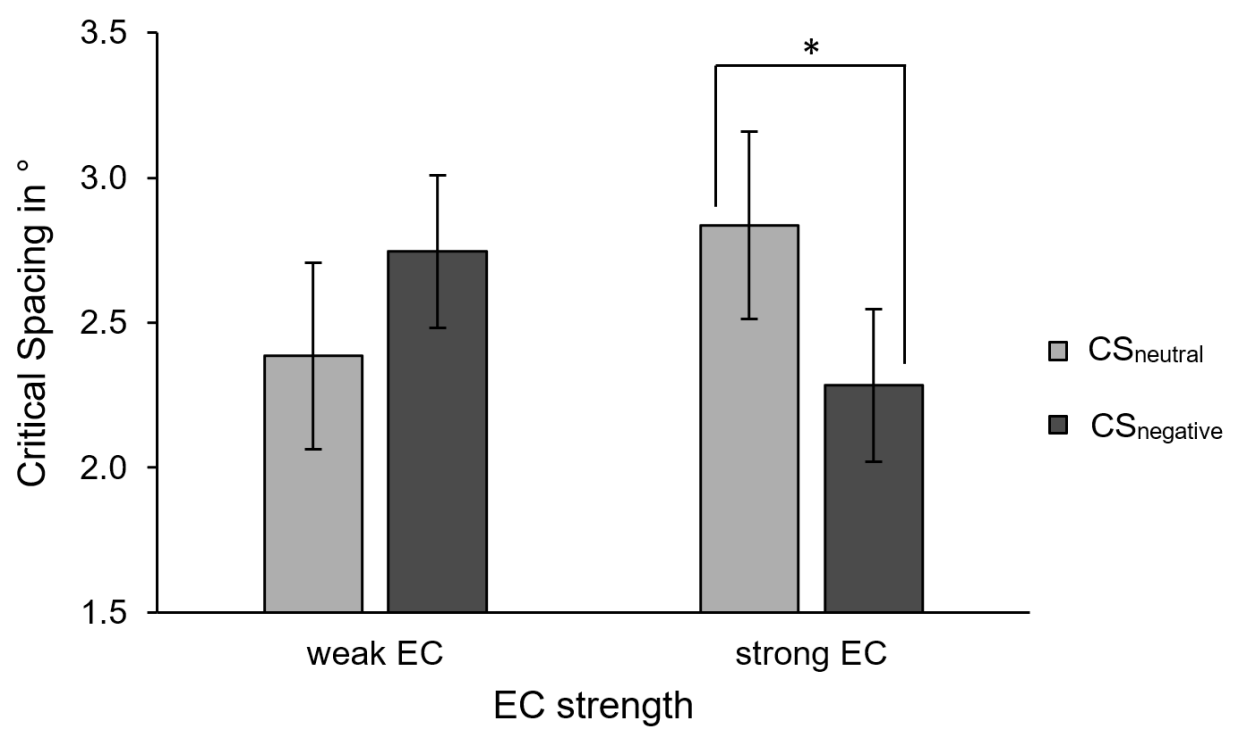

FIGURE 6.

Mean critical spacings (75\% thresholds) for conditioned target emotion and for weak and strong EC groups. Error bars indicate the SEM.

${ }^{*} p<.05$

2011). Following this logic, we expected to observe larger crowding effects for negative relative to neutral flankers. The analysis revealed larger critical spacings when the target was flanked by the $\mathrm{CS}_{\text {negative }}$ compared to the $\mathrm{CS}_{\text {neutral }}$. This effect indicates that $\mathrm{CS}_{\text {negative }}$ flankers impede target recognition to a larger extent than $\mathrm{CS}_{\text {neutral }}$ flankers. Previous research stressed that crowding effects depend on the amount of processing resources devoted to the flanker stimuli (e.g., Freeman et al., 2001). Thus, whenever participants pay more attention to the flankers, target identification suffers. There are numerous studies showing that emotional stimuli capture attention more strongly than neutral ones and that they are also more effective in holding attention (for an overview see, e.g., Yiend, 2010). Thus, attentional engagement towards emotional stimuli is facilitated and attentional disengagement from emotional stimuli is impaired compared to neutral stimuli. There are indications that this is also true for stimuli conditioned with aversive or negative stimuli (e.g., Batty et al., 2005; Koster et al., 2005). Thus, the $\mathrm{CS}_{\text {negative }}$ flankers might impair target identification because they withdraw processing resources from the target.

According to assumptions of prioritized processing of affective stimuli (Carretié, 2014; Yiend, 2010; Zadra \& Clore, 2011), we also expected less difficulty in identifying the $\mathrm{CS}_{\text {negative }}$ target relative to the $\mathrm{CS}_{\text {neutral }}$ target, that is, smaller critical spacings for $\mathrm{CS}_{\text {negative }}$ relative to $\mathrm{CS}_{\text {neutral }}$ target stimuli. Even though descriptively critical spacings were slightly smaller for $\mathrm{CS}_{\text {negative }}$ target stimuli, the overall difference was not statistically significant. However, the exploratory post hoc analysis suggests, interestingly, smaller critical spacings for $\mathrm{CS}_{\text {negative }}$ relative to $\mathrm{CS}_{\text {neutral }}$ targets for participants showing a strong EC effect. Since smaller critical spacings reflect easier recognition of the crowded target, the effect suggests that negatively valenced objects prevail and suffer less from interference by adjacent characters than neutral objects. The moderation of crowding by target emotion fits and links previous research on crowding and on emotion. Previous studies demonstrated that high-level semantic features of flanked stimuli are processed and yield effects on a task not related to crowding, for example, semantic priming effects or preference judgments (Atas et al., 2014; Faivre et al., 2012; Huckauf et al., 2008; Kouider et al., 2011; Yeh et al., 2012). Our work replicates and significantly extends these findings by suggesting that high-level features of crowded stimuli, that is, conditioned flanker and target emotion, are processed and can also directly impact the identification of the crowded target. Thus, it is remarkable that even though the recognition of the target stimulus is impaired, the effects of conditioned emotion are still observable. In line with the presumed prioritization of emotional stimuli (e.g., Carretié, 2014; Yiend, 2010; Zadra \& Clore, 2011), participants had less difficulty identifying the $\mathrm{CS}_{\text {negative }}$ relative to the $\mathrm{CS}_{\text {neutral }}$ targets. It seems plausible that this effect could be mediated by a difference in attentive processing of the CS. As mentioned above, emotion research suggests stronger attentional capture and holding by emotional compared to neutral stimuli, resulting in facilitated attentional engagement towards emotional stimuli and inhibited attentional disengagement from emotional stimuli (for an overview see, e.g., Yiend, 2010). This was also shown to be true for stimuli conditioned with negative, aversive UCS (e.g., Batty et al., 2005; Koster et al., 2005). In line with these findings, we observed easier identification of negatively conditioned target stimuli. In the context of the present study, this might suggest that even under deleterious crowding conditions, negative stimuli capture attention more strongly than neutral ones. However, it is, of course, important to bear in mind that this effect was only true for half of the subjects (i.e., those showing a strong EC effect) and therefore needs careful consideration in future research. The pattern of the present results invites speculation about the processes underlying crowding. In the current setting, stimulus emotion can only be effective after some critical stimulus features are identified. 
Hence, the data suggest that at least a part of the crowding effect arises after having identified the stimuli. Therefore, the results show that crowding cannot be solely explained by early, perceptual processes, but that later cognitive processes contribute to it as well (for an overview see Levi, 2008; Whitney \& Levi, 2011). In sum, the findings show that even though peripheral vision is degraded compared to foveal vision (e.g. Rosenholtz, 2016), semantic stimulus features such as stimulus emotion are processed and can even influence recognition performance.

It is worth highlighting that the effects were obtained by using evaluatively conditioned stimuli. The rather short EC procedure was sufficient in changing the processing of the formerly neutral Landolt rings. There is evidence suggesting that evaluatively conditioned stimuli elicit comparable responses to the affective UCS (e.g., Batty, et al., 2005; Kliegl et al., 2015; Pittino et al., 2016; Pittino et al., 2018). The present study extends these findings by demonstrating behavioral effects of EC in the crowding paradigm. Coherently with research on emotion (e.g., Carretié, 2014; Yiend, 2010; Zadra \& Clore, 2011), we observed prioritized processing of evaluatively conditioned stimuli resulting in greater distraction by $\mathrm{CS}_{\text {negative }}$ relative to $\mathrm{CS}_{\text {neutral }}$ flankers and facilitated identification of $\mathrm{CS}_{\text {negative }}$ compared to $\mathrm{CS}_{\text {neutral }}$ targets. Previous work on fear conditioning showed that stimuli paired with aversive UCS more easily capture and hold attention, which was reflected in faster reactions to the aversively conditioned stimuli (e.g., Koster et al., 2005). Extending these findings, our study demonstrated for the first time that even the identification of the stimuli is influenced by conditioned flanker and target emotion in the crowding paradigm. However, the effects of conditioned target emotion were only found for strong EC as assessed by evaluative ratings. Future research could enhance the effectiveness of the conditioning procedure by using more aversive stimuli in a fear conditioning procedure (e.g., shocks as UCS) and further assess its effectiveness by using multiple measures of the emotional response, that is, evaluative ratings and physiological measures. Future work should also consider assessing contingency awareness, that is, participant's knowledge about the relation between the CS and the UCS (Sweldens, Corneille, \& Yzerbyt, 2014). Even though there are studies suggesting that EC is independent of contingency awareness, other results do not support this conclusion (for an overview, see De Houwer et al., 2011, Hofmann et al., 2010; Sweldens et al., 2014). The meta-analysis of Hofmann et al. (2010) indicates that EC effects are at least stronger for subjects who are aware of the contingency between the CS and the UCS. Even though participants were instructed to pay close attention to the relation between the CS and the UCS, it is possible that those showing weak EC effects were not contingency aware. Future studies should consider including measures of contingency awareness (for an overview see Sweldens et al., 2014) and enhance contingency awareness by, for example, explicitly stating the relation between the CS and the UCS.

In the present study, we exclusively used negative stimuli in conditioning, since EC effects tend to be larger for negative stimuli (e.g., Levey \& Martin, 1975) and because the emotion literature hints at larger effects for negative stimuli (e.g., the negativity bias, Carretié, Mercado,
Tapia, \& Hinojosa, 2001). To overcome this current limitation, further research is needed to examine the impact of positive target and flanker emotion on crowding. Investigating the influence of both negative and positive target and flanker emotion would also allow to distinguish whether the effects are driven by valence or arousal (e.g., Schimmack, 2005). If mainly arousal causes the effects, one should observe similar results when using positive UCS. However, if the effects depend on the valence of the target and flanker stimuli, the effects should be different for positively conditioned target and flanker stimuli. One advantage of EC compared to fear conditioning in this context consists in the possibility to apply both negative and positive stimuli as UCS.

It is also necessary to identify possible boundary conditions of these effects. The present study suggests that the $75 \%$ threshold depends on flanker as well as on target emotion. One possible way forward in understanding the impact of affective factors on the processing of crowded stimuli may consist in varying the eccentricity of target presentation and target to flanker spacing. By doing so, one can investigate under which low-level target-flanker stimulus configurations the impact of flanker and target emotion can be found. In this regard, it might be particularly promising to determine the individual critical spacing before conditioning and administer this spacing in a visual crowding task after conditioning. This allows to replicate the present findings by analyzing the percentage of correct identification for conditioned flanker and for conditioned target emotion. Further, additional variations, that is, smaller and larger spacings, can give valuable insights into the interplay between low- and high-level influences on crowding.

In sum, the present study provides first evidence for the influence of emotion associated with flankers and targets on crowding. We observed larger crowding effects for negative relative to neutral flanker stimuli and reduced crowding effects for negative relative to neutral targets. However, the effect of target emotion was only evident for participants showing a strong EC effect and, therefore, appears to be weaker compared to the effect of flanker emotion. Thus, high-level features of crowded stimuli, that is, conditioned stimulus emotion, are processed and can also influence stimulus identification. The study also demonstrates that the evaluative conditioning paradigm can be successfully used to test the influence of emotion on rather early perceptual phenomena.

\section{ACKNOWLEDGEMENTS}

This research was partially funded by the LGFG-scholarship (scholarship according to the German Landesgraduiertenfoerderungsgesetz) awarded by Ulm University and by the SFB/TRR 62 "CompanionTechnology for Cognitive Technical Systems" awarded by the German Research Foundation (DFG).

\section{AUTHOR CONTRIBUTION}

F. Pittino and A. Huckauf developed the study concept and the study design. Data collection and preparing parts of the Method section was done by A. Kurz. F. Pittino performed the data analysis and interpretation under the supervision of A. Huckauf. F. Pittino drafted 
the manuscript and L.V. Eberhardt and A. Huckauf provided critical revisions.

\section{REFERENCES}

Atas, A., Faivre, N., Timmermans, B., Cleeremans, A., \& Kouider, S. (2014). Nonconscious learning from crowded sequences. Psychological Science, 25, 113-119. doi:10.1177/0956797613499591 إلسلس

Baeyens, F., Díaz, E., \& Ruiz, G. (2005). Resistance to extinction of human evaluative conditioning using a betweensubjects design. Cognition \& Emotion, 19, 245-268. doi:10.1080/02699930441000300 إلسلس

Batty, M. J., Cave, K. R., \& Pauli, P. (2005). Abstract stimuli associated with threat through conditioning cannot be detected preattentively. Emotion, 5, 418-430. doi:10.1037/15283542.5.4.418 سلس

Bouma, H. (1970). Interaction effects in parafoveal letter recognition. Nature, 226, 177-178. doi:10.1038/226177a0 布

Bradley, M. M., \& Lang, P. J. (1994). Measuring emotion: The selfassessment manikin and the semantic differential. Journal of Behavior Therapy and Experimental Psychiatry, 25, 49-59. doi:10.1016/0005-7916(94)90063-9 المالسلسل

Brainard, D. H. (1997). The Psychophysics Toolbox. Spatial Vision, 10, 433-436. doi:10.1163/156856897X00357 سلس

Carretié, L. (2014). Exogenous (automatic) attention to emotional stimuli: A review. Cognitive, Affective, \& Behavioral Neuroscience, 14, 1228-1258. doi:10.3758/s13415-014-0270-2 السلسل

Carretié, L., Mercado, F., Tapia, M., \& Hinojosa, J. A. (2001). Emotion, attention, and the 'negativity bias', studied through eventrelated potentials. International Journal of Psychophysiology, 41, 75-85. doi:10.1016/S0167-8760(00)00195-1 1/

De Houwer, J., Thomas, S., \& Baeyens, F. (2001). Associative learning of likes and dislikes: A review of 25 years of research on human evaluative conditioning. Psychological Bulletin, 127, 853-869. doi:10.1037//0033-2909.127.6.853 المالسلس

Faivre, N., Berthet, V., \& Kouider, S. (2012). Nonconscious influences from emotional faces: A comparison of visual crowding, masking, and continuous flash suppression. Frontiers in Psychology, 3, 129. doi:10.3389/fpsyg.2012.00129 الملسلسلئل

Freeman, E., Sagi, D., \& Driver, J. (2001). Lateral interactions between targets and flankers in low-level vision depend on attention to the flankers. Nature Neuroscience, 4, 1032-1036. doi:10.1038/nn728 سلس

Gawronski, B., Gast, A., \& De Houwer, J. (2015). Is evaluative conditioning really resistant to extinction? Evidence for changes in evaluative judgements without changes in evaluative representations. Cognition \& Emotion, 29, 816-830. doi:10.1080/0 2699931.2014 .947919 ||

Gawronski, B., \& Mitchell, D. G. V. (2014). Simultaneous conditioning of valence and arousal. Cognition \& Emotion, 28, 577-595. doi:10.1080/02699931.2013.843506 الس السلس

Hodsoll, S., Viding, E., \& Lavie, N. (2011). Attentional capture by irrelevant emotional distractor faces. Emotion, 11, 346-353.

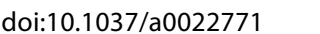

Hofmann, W., De Houwer, J., Perugini, M., Baeyens, F., \& Crombez, G. (2010). Evaluative conditioning in humans: A meta-analysis. Psychological Bulletin, 136, 390-421. doi:10.1037/a0018916 एلس

Horstmann, G., Borgstedt, K., \& Heumann, M. (2006). Flanker effects with faces may depend on perceptual as well as emotional differences. Emotion, 6, 28-39. doi:10.1037/15283542.6.1.28 الم

Huckauf, A., Knops, A., Nuerk, H.-C., \& Willmes, K. (2008). Semantic processing of crowded stimuli? Psychological Research, 72, 648-656. doi:10.1007/s00426-008-0171-5 السلسلسلة

Kliegl, K. M., Watrin, L., \& Huckauf, A. (2015). Duration perception of emotional stimuli: Using evaluative conditioning to avoid sensory confounds. Cognition \& Emotion, 29, 1350-1367. doi:1 0.1080/02699931.2014.978841 السلسلسلس

Kouider, S., Berthet, V., \& Faivre, N. (2011). Preference is biased by crowded facial expressions. Psychological Science, 22, 184-189. doi:10.1177/0956797610396226 المالسلسل الس

Koster, E., Crombez, G., Van Damme, S., Verschuere, B., \& De Houwer, J. (2005). Signals for threat modulate attentional capture and holding: Fear-conditioning and extinction during the exogenous cueing task. Cognition \& Emotion, 19, 771-780. doi:10.1080/02699930441000418 المالسلسل

Lakens, D., Fockenberg, D. A., Lemmens, K. P. H., Ham, J., \& Midden, C. J. H. (2013). Brightness differences influence the evaluation of affective pictures. Cognition \& Emotion, 27, 1225-1246. doi:1

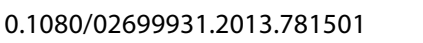

Lambert, A., Naikar, N., McLachlan, K., \& Aitken, V. (1999). A new component of visual orienting: Implicit effects of peripheral information and subthreshold cues on covert attention. Journal of Experimental Psychology: Human Perception and Performance, 25, 321-340. doi:10.1037/0096-1523.25.2.321 |Ш山ل|

Lang, P. J., Bradley, M. M., \& Cuthbert, B. N. (2008). International Affective Picture System (IAPS): Affective ratings of pictures and instruction manual. Technical Report A-8. Gainesville, FL: University of Florida.

Levey, A. B., \& Martin, I. (1975). Classical conditioning of human 'evaluative' responses. Behaviour Research and Therapy, 13, 221-226. doi:10.1016/0005-7967(75)90026-1 المالسلسل|

Levi, D. M. (2008). Crowding - an essential bottleneck for object recognition: A mini-review. Vision Research, 48, 635-654. doi:10.1016/j.visres.2007.12.009 سلس

Lipp, O. V., \& Purkis, H. M. (2006). The effects of assessment type on verbal ratings of conditional stimulus valence and contingency judgments: Implications for the extinction of evaluative learning. Journal of Experimental Psychology: Animal Behavior Processes, 32, 431-440. doi:10.1037/0097-7403.32.4.431 الهالسلسلة

Nazir, T. A. (1992). Effects of lateral masking and spatial precueing on gap-resolution in central and peripheral vision. Vision 
Research, 32, 771-777. doi:10.1016/0042-6989(92)90192-L Lلس السلسل Notebaert, L., Crombez, G., van Damme, S., De Houwer, J., \& Theeuwes, J. (2011). Signals of threat do not capture, but prioritize, attention: A conditioning approach. Emotion, 11, 81-89. doi:10.1037/a0021286 سلس

Parkhurst, D., Law, K., \& Niebur, E. (2002). Modeling the role of salience in the allocation of overt visual attention. Vision Research,

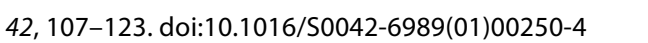

Pelli, D. G. (1997). The VideoToolbox software for visual psychophysics: Transforming numbers into movies. Spatial Vision, 10, 437-442. doi:10.1163/156856897X00366 الهلسلسلة

Pelli, D. G., Palomares, M., \& Majaj, N. J. (2004). Crowding is unlike ordinary masking: distinguishing feature integration from detection. Journal of Vision, 4, 1136-1169. doi:10.1167/4.12.12 سل

Pelli, D. G., \& Tillman, K. A. (2008). The uncrowded window of object recognition. Nature Neuroscience, 11, 1129-1135. doi:10.1038/nn.2187 البلسلس

Pittino, F., Kliegl, K. M., \& Huckauf, A. (2018). Subjective, physiological, and behavioral responses towards evaluatively conditioned stimuli. Cognition \& Emotion, 32, 1082-1096. doi:10.10

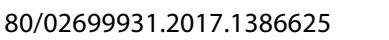

Pittino, F., Kliegl, K. M., \& Huckauf, A. (2016). The paradoxical conditioning effect of the human pupil might be evaluative in nature. Learning and Motivation, 55, 45-52. doi:10.1016/j.

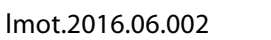

Rosenholtz, R. (2016). Capabilities and limitations of peripheral vision. Annual Review of Vision Science, 2,437-457. doi:10.1146/

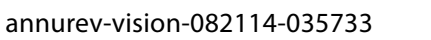

Schimmack, U. (2005). Attentional interference effects of emotional pictures: Threat, negativity, or arousal? Emotion, 5, 55-66. doi:10.1037/1528-3542.5.1.55 السلسلسلس

Schmidt, L. J., Belopolsky, A. V., Theeuwes, J. (2015). Attentional capture by signals of threat. Cognition and Emotion, 29, 687-

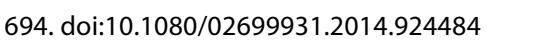

Stormark, K. M., Hugdahl, K., Posner, M. I. (1999). Emotional modulation of attention orienting: A classical conditioning study. Scandinavian Journal of Psychology, 40, 91-99. doi:10.1111/1467-9450.00104 السلس

Sweldens, S., Corneille, O., \& Yzerbyt, V. (2014). The role of awareness in attitude formation through evaluative conditioning. Personality and Social Psychology Review, 18, 187-209. doi:10.1177/1088868314527832 السلس

Watson, A. B., \& Pelli, D. G. (1983). Quest: A Bayesian adaptive psychometric method. Attention, Perception, \& Psychophysics, 33, 113-120. doi:10.3758/BF03202828 الس السلسلة

Whitney, D., \& Levi, D. M. (2011). Visual crowding: a fundamental limit on conscious perception and object recognition. Trends in Cognitive Sciences, 15, 160-168. doi:10.1016/j.tics.2011.02.005 |سلس

Yeh, S.-L., He, S., \& Cavanagh, P. (2012). Semantic priming from crowded words. Psychological Science, 23, 608-616.

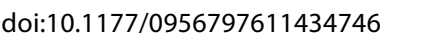

Yiend, J. (2010). The effects of emotion on attention: A review of attentional processing of emotional information. Cognition \& Emotion, 24, 3-47. doi:10.1080/02699930903205698 السلسلس الس الس

Zadra, J. R. \& Clore, G. L. (2011). Emotion and perception: The role of affective information. Wiley Interdisciplinary Reviews: Cognitive Science, 2, 676-685. doi:10.1002/wcs.147/ السلسلس 